\title{
DESIGN DE PRODUTOS E SERVIÇOS VOLTADOS AO USO COMPARTILHADO: percepções de designers e estudantes de design latino-americanos
}

\author{
Rosana A. Vasques \\ Doutoranda, FAU-USP, ravasques@gmail.com \\ Maria Cecília Loschiavo dos Santos \\ Professora Titular, FAU-USP, closchia@usp.br
}

\begin{abstract}
Resumo: Este trabalho apresenta os resultados de um workshop sobre design de produtos e serviços voltados ao uso compartilhado ministrado no VII Encuentro Latinoamericano de Diseño (Argentina, 2012). O workshop teve como objetivo apresentar conceitos fundamentais sobre o que é uso compartilhado, bem como suas implicações para o design desses sistemas, incluindo questões relacionadas à sustentabilidade e à diversidade cultural. Além disso, realizou-se a avaliação e discussão dos conceitos apresentados por meio de pesquisa prática com os participantes do workshop, com o desenvolvimento de propostas de produtos e/ou serviços de uso compartilhado, buscando identificar, entre eles, as diferenças culturais, barreiras e possibilidades de promoção de serviços e produtos de uso compartilhado.
\end{abstract}

Palavras-chave: uso compartilhado, design de produtos e serviços, diversidade cultural, América Latina.

Abstract: This paper presents the results of a workshop on the design of products and services for shared use taught at the VII Encuentro Latinoamericano de Diseño (Argentina, 2012). The workshop aimed to present basic concepts on what is shared use as well as its implications for the design of these systems, including issues concerning to sustainability and cultural diversity. In addition, we present an analysis and discussion of these concepts through a practice based research with the participants of the workshop that had developed proposals for shared use systems, seeking to identify, among them, cultural differences, barriers and opportunities to foster services and products for shared use.

Key words: shared use, product and service design, cultural diversity, Latin America 


\section{INTRODUÇÃO}

A necessidade de mudança nos padrões de produção e consumo, observada por diversos autores e amplamente divulgada na mídia, é uma das premissas para se alcançar um padrão de existência que não implique na degradação do planeta em um nível que seja impossível sua resiliência. Neste contexto, estratégias para o design de produtos ambientalmente sustentáveis propostas por Manzini e Vezzoli (2002) incluem: a desmaterialização de produtos e sua substituição por serviços; a eliminação de práticas de obsolescência programada; a extensão da vida dos materiais; o compartilhamento ao invés da posse, entre outras.

Além de promover a otimização da vida útil do produto e de contribuir para a redução dos níveis de produtos descartados em função de práticas de obsolescência, Manzini (2008) aponta que o uso compartilhado pode estimular novas formas de socialização e fomentar ações de inovação social que se inserem em um cenário de melhoria da qualidade de vida e de bem estar baseado na qualidade do contexto em que se vive ao invés da quantidade de posses.

A posse, no entanto, é descrita por Papanek (1995) como uma questão que vai além do acesso a bens, tanto em países desenvolvidos e em desenvolvimento quanto naqueles que fizeram parte do mundo socialista. Para este autor, a posse também é sinônima de pertencimento a uma determinada classe social ou a um status almejado. Desta forma, a posse está presente como símbolo de status social em todas as sociedades conhecidas. No entanto, Papanek esclarece que o consumismo e o desperdício são fenômenos gerados pela sociedade de consumo contemporânea, cujo princípio encontra-se na diversificação dos produtos no final do século XIX, período a partir do qual as empresas começam a utilizar o design como elemento de diferenciação e, posteriormente, de obsolescência programada, notadamente após a crise econômica de 1929 e a Segunda Guerra Mundial.

Por outro lado, Bostman e Rogers (2010) argumentam que, embora o hiperconsumo tenha sido a lógica de mercado dominante no século $X X$, fundamentada nas relações comerciais com base no crédito, na propaganda e no incentivo à posse individual, o século XXI será dominado por formas de consumo colaborativo, para as quais o valor está na comunidade, na reputação e no acesso compartilhado.

Além de discutir nossa relação com os objetos, que tem se mostrado cada vez mais associada às práticas de apego, individualismo e descarte, o uso compartilhado é, também, uma forma de questionar o papel do design(er) como agente político, cuja prática não é neutra, e, conforme argumenta Flusser (2008), é imbuída da responsabilidade e liberdade que são inerentes ao ato de criar.

Entende-se, assim, que a compreensão de barreiras socioculturais, bem como acerca das particularidades que devem ser consideradas ao se projetar produtos e serviços voltados ao uso compartilhado como propostas para a substituição da posse individual são de fundamental importância para que esses serviços sejam adotados em larga escala. Desta forma, poderá haver uma mudança efetiva nos modos de vida e de consumo atuais, originando formas significativas de consumo, com impacto positivo na promoção da sustentabilidade ambiental, econômica e social. 
Desta forma, o presente artigo resume os resultados da pesquisa exploratória realizada por meio de um workshop sobre uso compartilhado ministrado para designers e estudantes de Design. A pesquisa teve como objetivo tecer uma discussão inicial das propostas desenvolvidas no workshop em relação ao que é encontrado na literatura sobre o assunto, a partir da análise elaborada com os participantes. Embora limitada ao tempo do workshop e à quantidade de participantes, este estudo evidencia algumas particularidades sobre o projeto de produtos e serviços voltados ao uso compartilhado e esboça possibilidades de pesquisas futuras.

\section{WORKSHOP COMO MÉTODO DE PESQUISA}

A proposta de realização de um workshop ${ }^{1}$ sobre Design de Produtos e Serviços voltados ao uso compartilhado teve como objetivo contextualizar e apresentar conceitos fundamentais sobre esta forma de uso para designers e estudantes de design, bem como provocar a discussão sobre suas implicações projetuais, ressaltando algumas das particularidades requeridas pelo compartilhamento.

O workshop foi estruturado em três etapas: 1. Exposição sobre a base teórica (com duração aproximada de 30 minutos); 2. Realização de atividades de reflexão e prática projetual (com duração de 1 hora); 3. Apresentação e discussão das propostas de produtos e serviços desenvolvidos com os demais participantes (também com duração de 1 hora).

Foram sugeridas duas atividades aos participantes: a primeira, individual, buscou identificar itens que os participantes já compartilham ou gostariam de compartilhar e, em oposição, o que eles jamais compartilhariam ou sentiriam dificuldades em compartilhar. O objetivo desta primeira atividade foi o de identificar possíveis barreiras e facilitadores que poderiam impedir ou promover propostas de produtos ou serviços relacionados aos bens de consumo citados pelos participantes. Para que não houvesse influência nas respostas, esta atividade foi proposta após breve contextualização sobre uso compartilhado, que corresponde ao capítulo introdutório deste artigo - e o resultado foi apresentado somente ao final do workshop.

A segunda atividade, realizada em grupo, compreendeu o desenvolvimento de uma proposta de produto e/ou serviço voltado ao uso compartilhado, levando em consideração as diferenças ou similaridades culturais do grupo, que deveriam ser discutidas previamente.

A escolha do VII Encuentro Latinoamericano de Diseño ${ }^{2}$, para realização do workshop foi fundamentada na grande participação ${ }^{3}$ de estudantes e profissionais de design, de modo a obter uma amostra cultural relativamente diversificada para a coleta de dados sobre barreiras existentes no compartilhamento, bem como a identificação de quais objetos são mais facilmente compartilhados pelos participantes, enquanto consumidores. Por outro lado, também foi possível identificar algumas possibilidades de produtos e serviços voltados ao uso compartilhado que os

\footnotetext{
${ }^{1}$ O resumo do workshop consta nos anais do evento, publicado na Revista Actas de Diseño nำ14, Ano 7, 2013, p. 126.

${ }^{2}$ Realizado no período de 31 de julho a 03 de agosto de 2012, na Universidade de Palermo, em Buenos Aires, Argentina.

${ }^{3} \mathrm{O}$ evento, que ocorre anualmente, tem apresentado uma média de público de mais de cinco mil participantes, advindos de países de todos os continentes, mas principalmente dos países latino-americanos.
} 
participantes percebem como promissoras em seus contextos socioculturais, a partir da perspectiva desses enquanto designers.

Destaca-se que, ao todo, obteve-se 25 participantes na primeira atividade e 28 na segunda atividade, entre designers e estudantes de Design. Desses, apenas quatro já eram formados, sendo os demais graduandos em Design de Produto, Design Gráfico ou provenientes de cursos sem habilitação específica. Vale destacar que a sala destinada pela organização do evento comportava no máximo 30 pessoas.

No início do workshop, os participantes foram orientados sobre a utilização dos resultados (listas de produtos, propostas de produtos e serviços, bem como análises dos mesmos) para fins de pesquisa de doutorado e publicações relacionadas a esta pesquisa. Ao assinar o trabalho, os participantes autorizaram a publicação das imagens, conceitos desenvolvidos e nomes dos integrantes da equipe.

\section{USO COMPARTILHADO: BARREIRAS E FACILITADORES}

De acordo com Belk (2007), o compartilhamento, que é um comportamento culturalmente aprendido, pode estar presente em situações de excesso ou de insuficiência. No entanto, este autor argumenta que é muito mais fácil compartilhar bens imateriais, especialmente em formato digital, uma vez que o compartilhamento desses itens não incorre no risco de perdê-los, como no caso de livros, músicas e estórias. O materialismo, a posse individualista e a construção das identidades (self) com base nas posses, por outro lado, funcionam como inibidores ao compartilhamento.

Os 25 participantes desta atividade indicaram, ao todo, 39 itens como facilmente compartilhados e 37 itens que não compartilham ou jamais compartilhariam, sendo que alguns deles apresentaram mais de um item em suas respostas, por espontânea vontade.

Dentre os itens que foram apontados como aqueles cujos participantes já compartilham ou gostariam de compartilhar, destacam-se: livros e conhecimentos (18\%); comida e água (10\%); boas ideias (8\%); filmes, roupas e dinheiro (5\%). Os demais itens, que incluem casa, secador, carregador, entre outros, apareceram uma única vez (vide gráfico representado na Fig. 1).

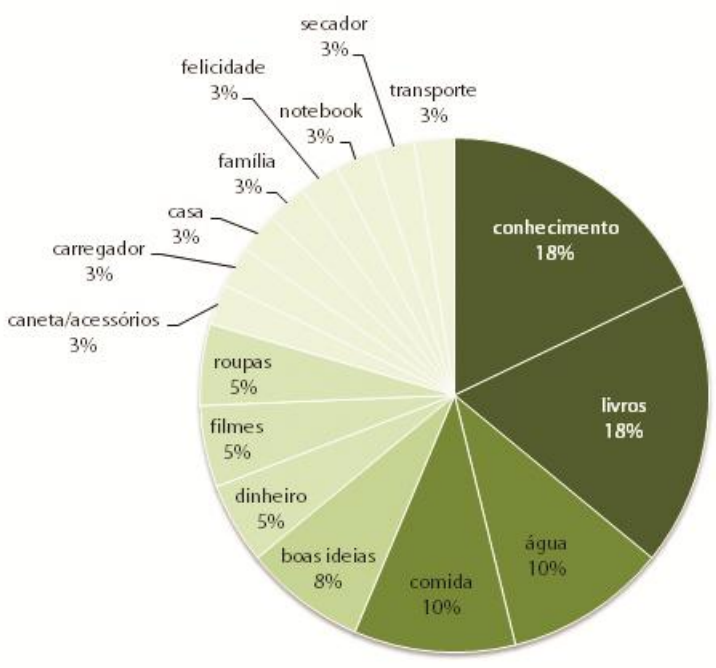


Figura 1 - Itens mais facilmente compartilhados na visão dos participantes

Fonte: Elaborado pela autora, com base na pesquisa realizada

Por outro lado, dentre os itens que dificilmente os participantes compartilhariam, encontram-se: objetos de higiene pessoal/escova de dentes (22\%); celular, computador/ notebook e roupas íntimas (11\%); Câmera fotográfica e banheiro (8\%). Os demais itens, de diversas categorias, receberam apenas um voto cada (Fig. 2).

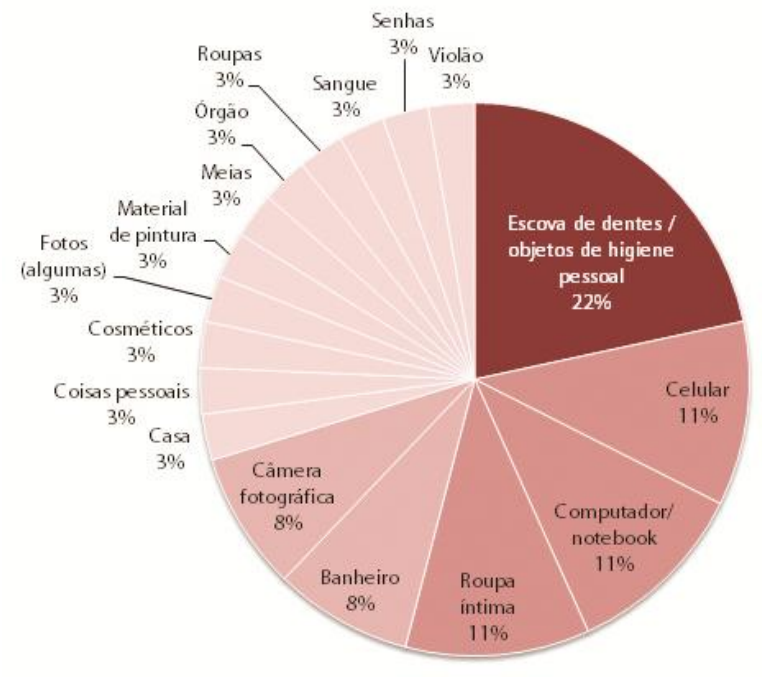

Figura 2 - Itens indicados pelos participantes como os mais difíceis de serem compartilhados Fonte: Elaborado pela autora, com base na pesquisa realizada

Com base nesses resultados, pode-se considerar que os participantes do workshop apresentam algumas barreiras em compartilhar produtos de uso pessoal e que envolvem noções de higiene, contaminação e poluição (materializados nos itens escova de dente, roupa íntima e banheiro), além de produtos de custo elevado (como notebook, computador, câmera fotográfica), possivelmente pelo risco de estragos que podem ser causados por outros usuários.

Interessante notar que os produtos descritos como aqueles que dificilmente os participantes compartilhariam vinham precedidos do pronome possessivo: "meu violão", "minha casa", "mi camara fotografica", reforçando a posse e o sentimento de apego em relação ao produto.

Vale ressaltar, ainda, a presença de itens como "sangue" e "órgãos" que foram citados dentre os itens que não são compartilhados, possivelmente por questões religiosas.

Por outro lado, os resultados sugerem que há maior facilidade em compartilhar bens virtuais, como conhecimento e boas ideias, confirmando o que sugere Belk (2007). Dentre os bens materiais, destacam-se aqueles que os participantes já têm o hábito de compartilhar, como livros, no meio universitário, e a água/comida, no âmbito familiar.

\section{PROPOSTAS DE PRODUTOS E SERVIÇOS VOLTADOS AO USO COMPARTILHADO}

Após a explanação acerca dos conceitos fundamentais sobre uso compartilhado e suas implicações para o design desses sistemas, foi solicitado que os 
participantes se reunissem em grupos para desenvolver uma proposta de produto e/ou serviço voltado ao uso compartilhado. Formaram-se, então, seis grupos, sendo que cinco deles eram mistos, isto é, cujos integrantes pertenciam a nacionalidades diversas, e um exclusivamente de integrantes paraguaios.

Não foi estabelecido o tipo de atividade que o produto ou serviço atenderia, de modo que os participantes pudessem discutir entre eles quais as oportunidades de negócios que eles identificavam como promissoras para a oferta de produtos ou serviços voltados ao uso compartilhado com base na realidade de seus países de origem.

Para o desenvolvimento do projeto, foi solicitado que a equipe definisse qual seria a oferta, acompanhada da justificativa para a mesma e público-alvo, além de apontar, se fosse o caso, a relevância cultural, social, econômica ou ambiental da proposta. Como não havia tempo suficiente para apresentar ferramentas e métodos específicos de Design de Serviços, optou-se por solicitar apenas uma representação gráfica da oferta. Foram disponibilizados pela organização do evento folhas de papel A2 e marcadores para a realização desta atividade.

Como resultado, os grupos apresentaram seis propostas de produtos e/ou serviços que visam o compartilhamento de bens materiais e/ou imateriais. Essas propostas são descritas e ilustradas nas subseções ${ }^{4}$ a seguir.

\subsection{Caneta leitora universal}

O primeiro grupo apresentou uma proposta de caneta leitora universal para ser usada de forma compartilhada entre pessoas com deficiência visual e analfabetismo, com o objetivo de ampliar a inclusão social e o compartilhamento de conhecimento. O produto, ilustrado na Fig. 3, seria disponibilizado em locais públicos, bibliotecas, escolas, livrarias e ONGs.

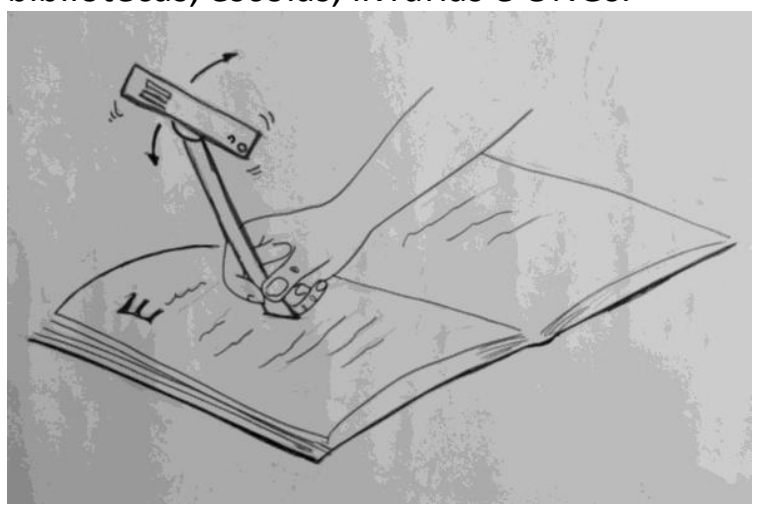

Figura 3: Caneta leitora universal

Designers: Gabriela, Alana e Leonardo (Brasil), Sandra (Chile), Angelica (Colômbia)

A proposta de produto deste grupo pode ser enquadrada na categoria de objetos que compartilhamos no cotidiano sem prestarmos atenção nesta forma de uso ou cujo compartilhamento é visto como comum, a exemplo de mesas em praças de alimentação, livros de bibliotecas, equipamentos de academia, entre outros.

\footnotetext{
${ }^{4} \mathrm{~A}$ ordem de apresentação das propostas neste artigo não seguiu a mesma realizada durante o workshop, que foi espontânea. Contudo, por fins didáticos, optou-se por denominar os grupos por números, descrevendo, aqui, primeiro as propostas que abrangem apenas produtos e, em seguida, as propostas que associam produtos e serviços ou abordam unicamente serviços de uso compartilhado, evidenciando, desta forma, o nível de complexidade das propostas.
} 
Por se tratar de um produto com princípios de design universal, os demais grupos entenderam que o objeto seria facilmente utilizado por diversas pessoas, adaptando-se aos requisitos dos diferentes usuários.

A ênfase nas funções prático-funcionais é considerada por Löbach (2001) como a mais adequada para o design de objetos de uso comum, uma vez que esses produtos devem "agradar" a maioria, considerando as necessidades gerais do grupo. Este autor indica que produtos de uso comum não permitem a produção de variantes, sendo necessário relegar a um segundo plano as funções simbólicas e estéticas. Santos (2004), no entanto, critica esta abordagem, considerando que mesmo os produtos de uso comum são carregados de simbologia.

\subsection{Secadora Solar}

O segundo grupo propôs um conceito de secadora solar (Fig. 4) para edifícios residenciais que possuem serviço de lavanderia coletiva, com base no hábito cultural brasileiro de ocultar as roupas íntimas lavadas nesses espaços (Vasques, 2011). Tal característica foi apresentada durante a etapa teórica do workshop, despertando o interesse do grupo. A equipe fundamentou a proposta principalmente em questões ambientais, como o uso da energia solar e o "design ecológico", por meio da indicação de materiais ambientalmente corretos.

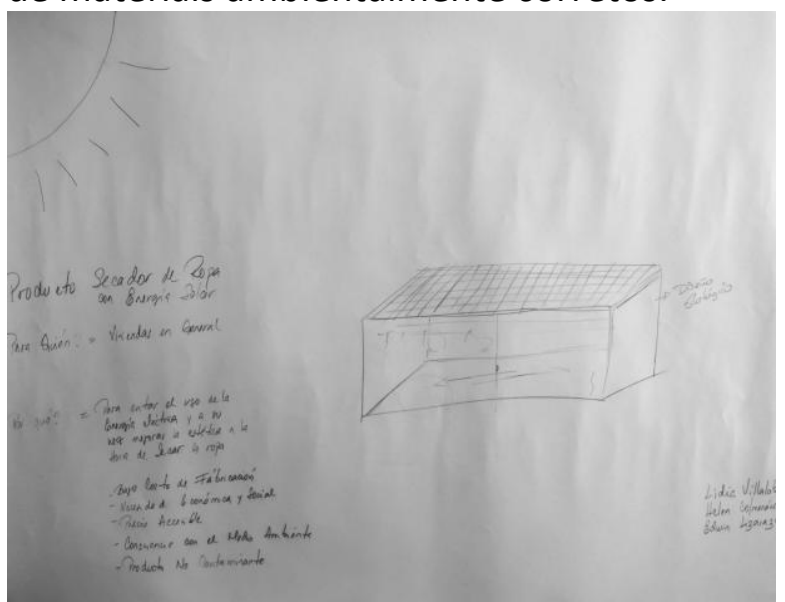

Figura 4: Conceito de secadora solar

Designers: Lidia (Chile), Helen e Edwin (Venezuela)

As demais equipes identificaram como facilitador para a viabilidade da proposta o fato desta apresentar um produto que também poderia ser vendido para uso doméstico, colocando em pauta a dimensão econômica da sustentabilidade, uma vez que, na lógica do produto, as empresas teriam maior interesse em produzir algo que pudessem vender mais unidades.

Outra abordagem seria agregar o serviço de manutenção na venda do produto ou, ainda, que este pertencesse à empresa e fosse alugado pelo condomínio, transformando-o em uma plataforma de serviço. Neste último caso, a empresa teria maior interesse na durabilidade do equipamento, um dos benefícios ambientais da substituição do produto por serviços.

Como barreira, foi apontada a indisponibilidade do produto durante o uso por outros moradores, assim como acontece com as lavadoras, quando não há uma programação ou agendamento prévio. 
Vale destacar que alguns participantes apontaram a questão da privacidade como relevante e comentaram que em seus países também não é comum deixar as roupas íntimas expostas. Por outro lado, outros explicaram que não se importam em expor as roupas íntimas e, assim como em alguns países europeus, não veem esta forma de exposição como um tabu.

\subsection{Serviço de compartilhamento de músicas regionais e informações turísticas}

A proposta do terceiro grupo refere-se a um serviço de compartilhamento de conhecimento, cultura e músicas regionais, além de informações sobre a cidade para turistas, por meio de totens urbanos, representado na Figura 5. A proposta é de que as informações possam ser acessadas no totem ou salvas em mídias de armazenamento de dados pessoais, que seriam ofertados pelo sistema, mediante pagamento de uma taxa.

Ao disponibilizar informações ou doar para o projeto pen-drives ou $m p 3$ players que não são mais utilizados, o usuário ganharia créditos para baixar outras informações e pontuação em seu perfil, gerando maior reputação no sistema.

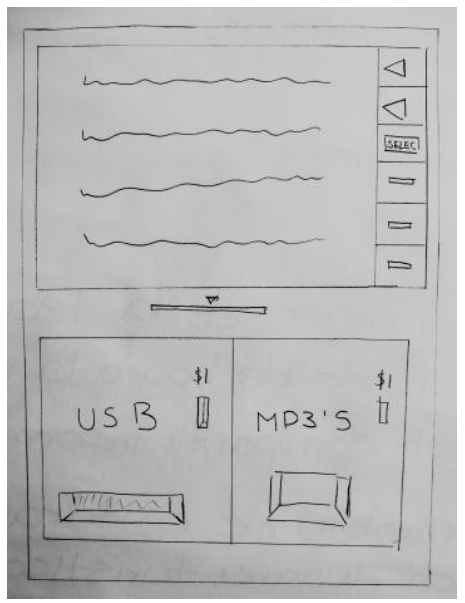

Figura 5: Esboço da interface para compartilhamento de músicas regionais e informações turísticas Designers: Macarena (Chile), Felipe (Brasil), Xavier (Espanha), Andrea e Ana Lucia (Peru).

O projeto parte da facilidade de compartilhar bens imateriais - como músicas e informações - e os associa ao compartilhamento de bens materiais (dispositivos de armazenamento de dados, como pen-drives e mp3 players), para os quais há uma maior dificuldade em compartilhar, conforme argumentado por Belk (2007).

Desta forma, o grupo apresentou um conceito de oferta viável e alinhada com a proposta de Schwartz (2010), que destaca a necessidade de se utilizar o design como uma ferramenta de promoção do uso compartilhado e não de impedimento. Essa autora propõe, ainda, que o design se aproprie da facilidade com que compartilhamos coisas online e utilize esse conhecimento para promover o compartilhamento off-line, tornando-o gratificante e simples.

\subsection{Compartilhamento de resíduos entre empresas}

A quarta proposta é direcionada para o setor empresarial/industrial (B2B), e explora, principalmente, a necessidade de destinar os resíduos industriais para o seu 
reaproveitamento ou reciclagem ao invés do descarte, evitando-se, desta forma, maior poluição do ar, da água e do solo.

Assim, a proposta deste grupo (Fig. 6) é de um serviço de gerenciamento, por meio de uma página de internet, para que empresas do mesmo país ou entre países latino-americanos compartilhem entre si seus resíduos, podendo gerar economia de recursos e melhorar o impacto ambiental das empresas participantes.

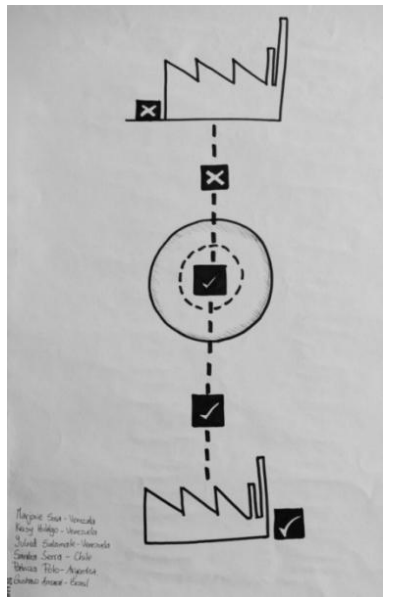

Figura 6 - Síntese da proposta de serviço de compartilhamento de resíduos entre empresas

Designers: Marjorie; Keisy; Yulied (Venezuela); Sandra (Chile); Patricia (Argentina); Gustavo (Brasil).

A principal barreira para adoção do serviço identificada pelos demais grupos durante a análise do serviço é a existência de legislação específica que impeça a entrada de resíduos advindos de outros países naquele que os receberá. A preocupação apresentada pelos participantes vai de encontro com a recomendação de Mont (2004), para a qual a existência de instituições regulamentadoras e normativas é essencial para a adoção de produtos e serviços de uso compartilhado.

\subsection{Aluguel de câmeras portáteis}

O serviço proposto pelo quinto grupo prevê o aluguel de câmeras fotográficas para turistas ou habitantes da cidade, permitindo o registro de momentos, fotos pessoais ou de paisagens e resolvendo o problema de quem não tem uma câmera em mãos, seja por não poder comprá-la ou por não dispor do equipamento naquele momento.

Tal serviço seria ofertado em quiosques de empresas patrocinadoras (service suppliers) que poderiam ser fabricantes de câmeras fotográficas (p. ex. Sony, Canon, Samsung, entre outras). O conceito de serviço proposto (Fig. 7) prevê as seguintes etapas (touch points) para seu funcionamento: 1. Necessidade de usar uma câmera e não dispor do produto, o que leva o usuário a buscar o serviço; 2. Pagamento de uma taxa pelo uso do serviço (por hora, tipo de equipamento etc.); 3 . Uso da câmera (período máximo de 8h); 4. Salvar ou imprimir as fotos e devolver a câmera ao quiosque mais próximo. 


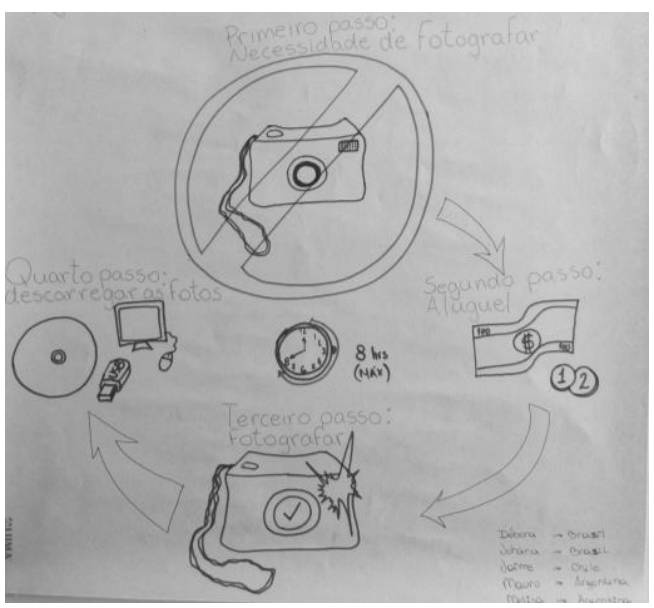

Figura 7 - Representação do serviço de aluguel de câmeras portáteis

Designers: Débora e Joana (Brasil); Jaime (Chile); Mauro e Melisa (Argentina)

Como facilitador para promoção do uso do serviço, foi sugerido que o quiosque poderia, ainda, oferecer serviços adicionais, como o de impressão de fotos, gravação de arquivos ou disponibilizar os arquivos digitais em uma página da internet para download futuro.

Como medida de segurança, o grupo propôs a assinatura de um termo de responsabilidade, no qual o usuário compromete-se a pagar uma multa previamente estabelecida em caso da não devolução do equipamento. Outra possibilidade de medida de segurança que poderia ser adotada para este tipo de serviço seria o depósito de um "cheque-caução" ou débito em cartão de crédito no valor do equipamento no momento da sua retirada, como é feito em outros serviços de uso compartilhado.

\subsection{CulTuPlaza}

O sexto grupo, formado unicamente por paraguaios, propôs um serviço de compartilhamento cultural, tendo em vista o baixo índice de leitura e alto índice de analfabetismo funcional do país, conforme relatado pelos integrantes do grupo. Desta forma, CulTuPlaza - praça da cultura para você - (Fig. 8) é uma proposta de sistema que promove a troca e empréstimo de livros, filmes, jogos, músicas e internet para pessoas que não dispõem de recursos para adquirir ou ter acesso a tais produtos e serviços.

Nas palavras do grupo, os objetivos do sistema são: "a) fomentar la lectura, conocimientos básicos, y hacer que la lectura sea parte de la población en general; b) generar un ambiente solidario, de compartir conocimientos y cosas materiales." 


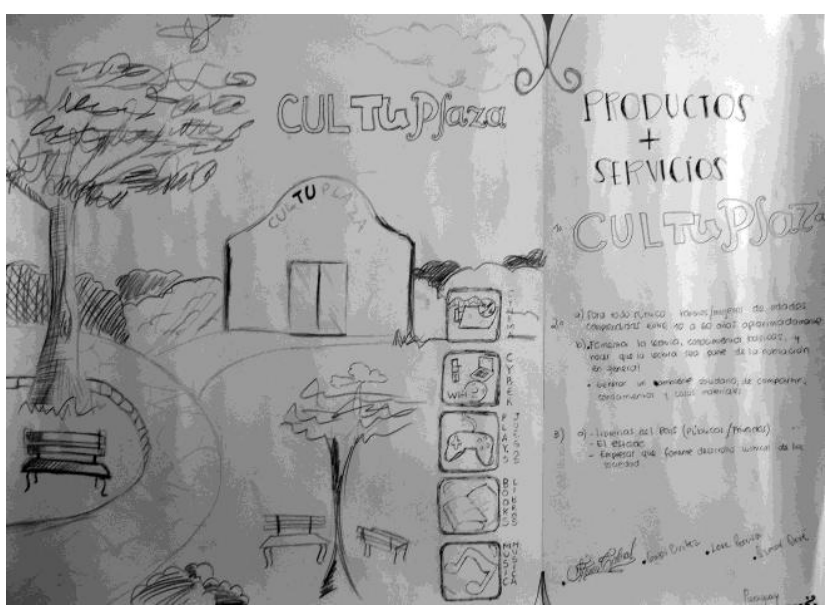

Figura 8 - CulTuPlaza - proposta deproduto + serviço para o compartilhamento cultural Designers: Aeron, Gabi, Lore, Osmar (Paraguai)

Durante a discussão entre os grupos, identificou-se que a principal barreira para uso e adoção do serviço CulTuPlaza seria a questão da segurança, tendo em vista a criminalidade presente em locais públicos, realidade relativamente comum entre os países de todos os participantes do workshop.

\section{CONSIDERAÇÕES FINAIS}

Este trabalho buscou apresentar e discutir os resultados de um workshop realizado como método de pesquisa sobre hábitos de compartilhamento latinoamericanos, destacando-se as barreiras e particularidades do design voltado ao uso compartilhado neste contexto, além de explorar possibilidades de promoção desta forma de uso como alternativa de consumo sustentável, por meio da percepção de designers e estudantes de design que participaram do VII Encuentro Latinoamericano de Diseño, em Buenos Aires, Argentina.

Quanto aos resultados da primeira atividade, embora os dados confirmem teorias previamente consultadas, sugere-se a necessidade de investigar, em pesquisas futuras, as razões que motivam os participantes a indicarem determinados bens como mais facilmente compartilhados e outros como impossíveis de compartilhar, incentivando-os a apresentarem seus próprios argumentos para essas escolhas.

No que concerne aos resultados da segunda atividade, é preciso considerar que a disciplina de Design de Serviços é relativamente nova nos cursos de Design nos países da América Latina, quando não inexistente, o que justifica a dificuldade de alguns grupos em pensarem na proposta de compartilhamento enquanto um serviço e mesmo na sua representação gráfica. Como o workshop não apresentava conteúdo específico sobre métodos de Design de Serviços, em função do tempo máximo no qual a atividade poderia ser desenvolvida, e conhecendo previamente a realidade dos participantes, não foi exigido o projeto de um sistema ou de serviço, o que deu margem, em alguns casos, para a ênfase no produto.

Em contrapartida, algumas equipes conseguiram representar bem o conceito do produto associado ao serviço, sintetizando visualmente o funcionamento da proposta e apresentando ideias alinhadas com as características de seus contextos socioculturais. 
Neste sentido, a proposta CulTuPlaza de compartilhamento de livros, filmes, músicas, jogos etc., é um bom exemplo de adequação ao contexto latino-americano, pois abordou tanto um problema social, isto é, a deficiência nos índices de leitura do país, quanto o acesso à equipamentos que dão suporte à rede e que podem propiciar o compartilhamento online. Além disso, a proposta parte de uma prática comum entre círculos menores de amizade, ou da família ampliada (Belk, 2007), que pode ser expandido para outras atividades cotidianas.

Com relação à proposta de serviço de compartilhamento de câmeras fotográficas, é interessante notar que, embora não tivesse comentado com os participantes até o momento da apresentação deste conceito, a autora estava utilizando uma câmera compartilhada durante o evento, pois não dispunha de uma câmera pessoal naquele momento.

Ressalta-se, ainda, que a segunda atividade poderia ter resultados que evidenciassem questões culturais específicas de cada país, caso os grupos assim fossem divididos, como pareceu sugerir a proposta elaborada pelo grupo formado apenas por paraguaios.

Vale notar que os países latino-americanos têm, especialmente a partir da segunda metade do século XX, importado modelos de produção e consumo dos países industrializados (Ono, 2006; Gonzales, 2012), notadamente o consumo de massa, que consequentemente se traduz na adoção de um sistema de valores e princípios contrários à sustentabilidade.

Assim, as propostas apresentadas pelos participantes são de fundamental relevância para a construção de uma quebra de paradigmas relacionados à atividade projetual para os participantes, enquanto designers e também como consumidores, uma vez que as propostas apresentadas são factíveis e sugerem ideias de produtos e serviços promissores no contexto latino-americano, que poderiam contribuir com a mudança de hábitos e valores para práticas mais colaborativas.

\section{Agradecimentos}

As autoras agradecem ao CNPq e à Comissão de Pós-Graduação da Faculdade de Arquitetura e Urbanismo da Universidade de São Paulo, pela bolsa de pesquisa de doutorado concedida (Proc. 143155/2011-3). Destaca-se, também, o apoio da Universidad de Palermo (Buenos Aires - Argentina) e da equipe de organização do VII Encuentro Latinoamericano de Diseño para a realização do workshop que deu origem a este trabalho.

\section{REFERÊNCIAS}

BELK, R. W. Why not share rather than own? The ANNALS of the American Academy of Political and Social Science. v. 611, n. 1, p. 126-140, May 2007. doi: 10.1177/0002716206298483.

BOSTMAN, R.; ROGERS, R. What is mine is yours: the rise of collaborative consumption. New York: HarperCollins Publishers, 2010. 
FLUSSER, V. Design: obstáculo para a remoção de obstáculos? In: O mundo codificado. São Paulo: Cosac Naify, 2008.

GONZALES, M. A. Sustentabilidad en la cultura material ¿ Está la sociedad preparada para afrontar de forma real el desarrollo sustentable? Foroalfa. Disponível em: http://foroalfa.org/articulos/sustentabilidad-en-la-cultura-material. Acesso em 03 out. 2012.

LÖBACH, B. Design industrial: bases para a configuração dos produtos industriais. São Paulo: Edgard Blücher, 2001.

MANZINI, E.; VEZZOLI, C. O desenvolvimento de produtos sustentáveis: os requisitos ambientais dos produtos industriais. São Paulo: Edusp, 2002.

MANZINI, E. Design para a inovação social e sustentabilidade: comunidades criativas, organizações colaborativas e novas redes projetuais. Rio de Janeiro: E-papers, 2008.

MONT, O. Institutionalisation of sustainable consumption patterns based on shared use. Ecological Economics. v. 50, issues 1-2, p. 135-153, Set. 2004. doi:10.1016/j.ecolecon.2004.03.030.

ONO, M. M. 2004. Design industrial e diversidade cultural: sintonia essencial. Estudos de casos nos setores automobilístico, moveleiro e de eletrodomésticos no Brasil. Tese de Doutorado. Faculdade de Arquitetura e Urbanismo, Universidade de São Paulo.

PAPANEK. V. Alugar e não comprar. In: Arquitectura e Design: ecologia e ética. Lisboa: Edições 70, 1995.

SANTOS, M. R. dos. Design e cultura: os artefatos como mediadores de valores e práticas sociais. In: QUELUZ, M. L. P. (Org). Design \& cultura. Curitiba: Editora Sol, 2004.

SCHWARTZ, K. From designing for ownership to designing for sharing. (07.07.2010). Shareable. Disponível em: < http://www.shareable.net/blog/from-designing-forownership-to-designing-for-sharing >. Acesso em: 28 fev. 2012.

VASQUES, R. A. 2011. Design, Cultura e Sustentabilidade: um estudo sobre uso compartilhado em lavanderias coletivas de edifícios residenciais em Curitiba-PR. Dissertação de mestrado não publicada. Programa de Pós-graduação em Design, Universidade Federal do Paraná. 